\title{
O HISTORIADOR MAX WEBER: INDOLOGIA E HISTORICISMO NA OBRA WEBERIANA
}

\author{
Arilson Silva de Oliveira \\ Doutorando em História Social pela Universidade de São Paulo (USP).*
}

\begin{abstract}
Resumo
Max Weber apropriou-se das exigências metodológicas do historicismo alemão contra toda filosofia iluminista natural e toda filosofia idealista da história. Ele as depurou no intuito de evitar as conclusões do romantismo e os desvios psicologistas do neo-historicismo. Aqui, observamos como ele muniu-se de um método particular, resgatou a racionalidade e a utilizou como parâmetro para compreender historicamente a sociedade indiana frente ao historicismo desencantado de sua época.
\end{abstract}

\section{Pallavras-chave}

Max Weber • indologia • historicismo • teoria da história.

\section{Abstract}

Max Weber assumed the methodological requirements of German historicism against all natural illuminist philosophy and all the idealistic philosophy of history. He improved them in order to prevent the conclusions of the romanticism and the psychological deviations of the neo-historicism. Here, we observe how he equipped himself with a particular method, rescued rationality and applied it as a parameter to historically understand Indian society in opposition to the disenchanted historicism of his time.

\section{Keywords}

Max Weber $\bullet$ indology $\bullet$ historicism $\bullet$ theory of history.

* Órgão financiador: Fapesp. 


\section{Introdução}

Os estudos sociológicos em geral se apropriam de Max Weber como um de seus autores fundadores, ou seja, como um eminente (e já clássico) precursor, com inúmeras e variadas contribuições às ciências sociais. Entretanto, aqui, visamos apresentá-lo como também proeminente teórico da história, pela identificação de conceitos e princípios advindos de suas análises indológicas, abundantemente presentes em uma de suas principais obras: Hinduismus und Buddhismus (1921, póstumo), ainda pouco conhecida ou quase ignorada pelos estudos weberianos, sobretudo no Brasil.

Hoje em dia é muito comum afirmar que Weber fez uma sociologia histórica. O que devemos nos perguntar é se esse hibridismo poderia ser reconhecido pelos homens de ciência no início do século XX. Parece-nos que não. E se nos inclinamos para a negativa, em oposição a essa leitura atual, é porque temos o intuito de evitar determinado anacronismo. Weber é, além de pensador da sociedade, um exímio teórico da história. $\mathrm{E}$ isto serve à sua própria estratégia metodológica, já que concebia a sociologia como auxiliar da história. Defendemos que resgatar a importância do Weber historiador não implica em negar seu viés sociológico, mas recuperar também a obra do historiador, obscurecida pela sua apropriação nas ciências sociais. ${ }^{1}$

\footnotetext{
Não apenas em obras recentes, tão bem construídas e tão bem argutas, como Orientalism and religion de Richard King, por exemplo, o qual não dedica uma única referência ou crítica à indologia weberiana, uma vez que Weber lhe havia servido de exemplo e contraexemplo para muitas de suas afirmações. Ademais, Weber chega a ser silenciado por seus compatriotas como Helmuth von Glasenapp, o qual, em seu pioneiro Das Indienbild Deutscher Denker se detém, com certa extensão, em múltiplos autores que não têm o fôlego intelectual de Weber. Ou como Wilhelm Halbfass, que, nas 550 páginas de sua referencial Indien und Europa, tão só inclui uma triste alusão a Weber numa nota final. [HALBFASS, W. Indien und Europa. Perspektiven ihrer geistigen Begegnung. Stuttgart: Schwabe \& Co AG Verlag, 1981, p. 521], referida à problemática da carência do direito natural na Índia. Sem falar do weberólogo Fritz Ringer, o qual elaborou uma exaustiva e minuciosa análise de Weber em Max Weber's methodology, 1997 [Metodologia de Max Weber: unificação das ciências culturais e sociais. São Paulo: Edusp, 2004], mas não fez uma única menção ao método indológico weberiano, tocando no assunto apenas em An intellectual biography. Chicago: The University of Chicago Press, 2004; mas com um breve resumo. No Brasil, o weberólogo Flávio Pierucci chegou a escrever sobre a China e o Islã, mas nunca sobre a Índia. Jessé de Souza também já escreveu abundantemente e organizou obras sobre Weber, mas não existe um único olhar direcionado para a Índia pela via de Weber. Tudo isso, provavelmente, desmotivado pela falta de conhecimento indológico e pela incompreensão da abundante língua sânscrita utilizada por Weber.
} 
Para caracterizar essa recuperação, utilizamos a história filosófica e indológica weberiana, em geral ignorada ou lida apressadamente, mal compreendida, mal apropriada e visivelmente sugerida como secundária. Indicamos que a função da indologia weberiana, assim como toda a sua obra, volta-se, dentre outros interesses, para a compreensão das particularidades da sociedade ocidental moderna; notadamente, o desencantamento sem precedente ocidental será identificado por contraste com a Índia encantada, ou seja, dois extremos que facilitam uma comparação tipo ideal, por assim dizer.

A nossa pergunta-guia é se o segundo volume (dentre três) de Gesammelte Aufsätse zur Religionssoziologie (GARS), obra indológica de Weber, consiste mesmo em uma obra sociológica ou histórica.

Nosso foco central, em si, é muito simples: Hinduismus und Buddhismus é uma obra de história, a qual ampara uma das principais oposições teóricas weberianas: desencantamento versus encantamento do mundo. A Índia figura como tipo ideal do encantamento, contra o desencantamento proliferado pelo protestantismo europeu, com o advento do puritanismo e do calvinismo, tão lucidamente analisados em sua também clássica obra - histórica e não sociológica, segundo Sérgio da Mata: ${ }^{2}$ Die protestantische Ethik und der "Geist" des Kapitalismus [A ética protestante e o "espírito" do capitalismo] (1904-5, 1920).

Esse desencantamento ou processo histórico-religioso, segundo Weber, teve início com as profecias do judaísmo antigo - com seu dogma emissário de interpelação ética - em conjunto com o pensamento científico helênico (estóico-semítico, ${ }^{3}$ com a prática sobrelevando a teoria). Tal processo rejeitou os meios da racionalização mística (contemplação intelectiva), tendo como efeito o Entgötterung der Natur [desendeusamento da natureza] e deixando no espírito um vazio e um mundo submetido meramente ao ganho e ao interesse material, ${ }^{4}$ não obstante, instalando a insatisfação de um tempo presente permanente, um

2 MATA, Sérgio da. O mito de A ética protestante e o espírito do capitalismo como obra de sociologia. In: Locus, revista de história. Juiz de Fora, v. 12, n. 1, 2006, p. 113-126.

3 Russel afirma que "a preparação psicológica do cristianismo para a outra vida começa no período helenístico", fato que o faz observar: "até Aristóteles, os filósofos gregos, embora pudessem queixar-se disto e daquilo, não se sentiam, em modo geral, cosmicamente desesperados, nem se achavam politicamente impotentes". Pois, completa Russel, Aristóteles é o último filósofo grego que enfrenta o mundo alegremente. RUSSEL, Elucida Bertrand. História da filosofia ocidental, vol. I. São Paulo: Companhia Editorial Nacional, 1957, p. 268 e 271.

4 WEBER, Max. A ética protestante e o "espirito" do capitalismo. São Paulo: Companhia das Letras, 2004, p. 96. 
amanhã sempre ausente e um passado atrasado que se deve esquecer. Ou seja, o grau com que as ideias judaico-cristãs se despojaram da magia, eliminando os significados da vida cotidiana, tendo como mediador ou afinidade eletiva a técnica helenística e como ponto de chegada ou fim (Abschluss) a cruzada puritana, com sua divinização do trabalho - "pirataria, só isto!", dirá Nietzsche - e seu ethos racional finalista como meio para o vazio de um pluralismo cognoscitivo recheado de Nada (como dirá Weber). Tudo isso explica, segundo Weber, como tal ilusão progressista e desencantada adentrou o campo científico e filosófico (ou mecanismo causal desprovido de sentido) da racionalização do mundo e criou ou provocou, dentre outras coisas, falsas ideias sobre as ideias do Oriente $^{5}$ ou falsas ideias longe do que não se percebeu ou alcançou do Oriente como sendo ideias primais e complexamente desenvolvidas.

Tal sintagma (desencantamento do mundo), entendido como desmagificação ou desracionalização do pensamento místico, representa a função, portanto, de um processo histórico grandioso e especificamente ocidental, quase à guisa de um nome próprio e não comum, o enorme e peculiar período de racionalização alcançada por esta forma de moral monótono-teísta, como inferirá Nietzsche.

Para o weberólogo Wolfgang Schluchter:

Somente quando o protestantismo em consequência da reforma retomou as heranças judaicas e cristãs primitivas - amalgamando-as sobre o fundamento de um individualismo religioso radical - pôde acontecer [...] o desencantamento (Entzauberung) radical [...]. Nesse sentido, Weber pode afirmar o fato de somente aqui ser realizado o desencantamento completo do mundo com todas as consequências [incluso a invenção e difamação do Oriente e o rechaço da filosofia]. ${ }^{6}$

Para entendermos esse significativo ponto da teoria weberiana, na Inglaterra, por exemplo, a magia de um modo em geral perdeu sua força social antes mesmo que a maquinaria técnica em grande escala (industrial) fosse criada no intuito de substituí-la. Foi o "abandono" da magia que possibilitou/facilitou a erupção da tecnologia mecanicista e não o contrário. Na verdade, como eloquentemente nos apresentou Weber, a magia era potencialmente um dos maiores obstáculos

\footnotetext{
5 Logicamente, com suas devidas exceções.

6 SCHLUCHTER, Wolfgang. As origens do racionalismo ocidental. In: SOUZA, Jessé (org.). $O$ malandro e o protestante: a tese weberiana e a singularidade cultural brasileira. Brasília: Editora UNB, 1999, p. 113.
} 
(muitas vezes conscientes, como no caso indiano e chinês) à racionalização da vida econômica tecnocrata, sendo desobstruída com a fundição entre a racionalidade neo-helênica europeia e a doutrina protestante, como uma providência do mal-estar histórico, dirigido pela visão de mundo em "nego-ócio" ou negação do ócio como prerrogativa do desencantamento do mundo. Esse reino mecanicista, no qual os efeitos seguem as causas de maneira previsível e calculista, sem o auxílio de uma visão mística racional que o detecte.

Por isso, Weber (sob a sombra de Marx que afirmara ser o capitalismo um judaísmo prático ou Judentum) é o único, dentre os autores germânicos clássicos, ${ }^{7}$ que rompe em definitivo com as premissas da filosofia da história hegeliana, bem como das hipóteses fundamentais do evolucionismo darwiniano. Não por acaso, Weber ironicamente dirá: "ao contrário do que pensam os otimistas [evolucionistas] entre nós, vê-se que nem sempre a seleção realizada num livre jogo de forças acaba beneficiando a nacionalidade mais desenvolvida ou melhor dotada economicamente". ${ }^{8}$ Ao mesmo tempo, lamenta a queda da "magnificência marmórea" da Antiguidade: "comove-nos melancolicamente o espetáculo de uma evolução que, ao aspirar o mais alto, perde sua base material e rui sobre si mesma". 9

Tal observação leva Luís Gusmão a elucidar:

Weber está perfeitamente consciente de que o mundo dos homens é o mundo da ação intencional, isto é, da ação orientada por crenças e propósitos, dos significados culturais intersubjetivamente partilhados, dos valores e das normas, e não o mundo das forças cegas, das regularidades e dos autonomismos naturais que vinham, desde o século XVII, sendo objeto de um rigoroso e abstrato saber nomológico. Neste reconhecimento, lúcido legado do ponto de vista historicista, Weber se afasta da crença filosófica [hegeliana], tão explicitamente professada por Durkheim em seus textos metodológicos e, ao nosso ver, implícita na obra marxiana, segundo a qual as regularidades e invariâncias, indubitavelmente presentes na vida social, autorizariam o projeto de uma sociologia causal e determinista, voltada para o estabelecimento de leis tão gerais e inflexíveis como aquelas encontradas no âmbito das ciências naturais. ${ }^{10}$

7 Podemos citar outros expressivos ou menos conhecidos autores alemães que inferiram acerca de tal relação histórica entre protestantismo e capitalismo, como, por exemplo, Werner Sombart em The Jews and modern capitalism, 1911.

8 COHN, Gabriel(org.). Weber. Coleção Grandes Cientistas Sociais, n. 13. São Paulo: Ática, 1999, p. 65.

9 Ibid., p. 56.

${ }^{10}$ GUSMÃO, Luís. A concepção de causa na filosofia das ciências sociais de Max Weber. In: 
Weber, portanto, concebeu a modernização (lê-se "espírito do capitalismo": alfa e ômega da moral auri sacra fames) social da velha deusa Europa como resultado de um processo histórico de racionalização ou mecanização das relações sociais, o qual se manifestou com o sagrado auxílio (com afinidade eletiva) de um terreno fértil chamado protestantismo, que, por sua vez, determinara que o lucro fosse um ato natural, podendo ele ser praticado sem o chamado especial de seu deus e que o indivíduo ou o eu individual, in majorem Dei gloriam, não pode e não deve divinizar a criatura (no caso, o homem) através das relações pessoais e com caráter místico-racional. Não será por acaso que Nietzsche ${ }^{11}$ definirá o protestantismo como a hemiplegia (paralisia parcial ou total do corpo) da razão.

\section{0 historicismo alemão}

A extenuante formação da ciência histórica e social alemã está marcada pelo debate original, largo e intricado entre o Iluminismo (Aufklärung) e o historicismo (Historismus), "surgido" a propósito da Revolução Francesa e reforçado com a revolução fracassada de 1848. E uma de suas investidas principais e decisivas foi repensar a relação entre filosofia e tempo, razão e história. Um inegável mérito do pensamento alemão também foi a reivindicação do "pensar-se na história" em oposição ao "pensar-se como homem" (legado do antropocentrismo renascentista europeu). Ante esse intenso turbilhão intelectual, a defesa alemã do "histórico" foi entendida como o equivalente a uma tomada de partido lúcida: pela tradição, pelo passado e pela restauração de uma cultura perdida. Todavia, o histórico não se esgotou com esta mudança, senão que inaugurou a cultura alemã do século XIX, determinando, assim, sua tensão com o resto da Europa $^{12}$ e seu riquíssimo debate filosófico.

Em geral, a crítica historicista alemã contra o Iluminismo centrou-se na separação que este último havia estabelecido entre razão e história (interpretando a historiografia como arte). A razão, no Iluminismo, havia desembocado num conceito abstrato da "natureza humana" e seu conceito pretendia ser a forma e a norma dos fatos sociais. Todavia, os alemães cuidaram para que a intelectualida-

SOUZA, Jessé. A atualidade de Max Weber. Brasília: UNB, 2000, p. 244.

${ }^{11}$ NIETZSCHE, Friedrich W. O anticristo \& ditirambos de Dionisio. São Paulo: Companhia das Letras, 2007, § 10.

${ }^{12}$ Em torno de 1800, deu-se uma revolução (podemos assinalar: uma "re-volta") educacional nos estados germânicos; portanto, anterior a Inglaterra e a França e bem antes da devastação do homo faber alcançar a Germânia (fato instalado pelos nazistas ao advento das grandes guerras no século XX). 
de e as relações de poder (Estado) chegassem a uma "verdade" particular e separada: vigorosa especulação intelectual versus devoção apolítica. Na Alemanha, o apriorismo de Kant era o paradigma desta separação: lugar de manifesto na desarticulação que o mesmo Kant havia estabelecido entre teoria e prática da razão.

O historicismo enfrentou essa tese de Kant com a afirmação de que, por um lado, a unidade do conceito de natureza humana não contém a riqueza da pluralidade e das diferenças históricas, nacional-populares, culturais e individuais, e, por outro, que sua identidade prescinde das contradições e dos conflitos reais. ${ }^{13}$

Dentro do debate entre Aufklärung e Historismus coloca-se também a questão do determinismo e da teleologia. Kant será o ponto de partida dessa questão com sua afirmação da dupla causalidade na história: os fatos históricos enquanto "fenômenos", "objetos de conhecimento", não podem ser conhecidos além de causas-efeitos, sob o princípio do determinismo; enquanto "ações humanas", por outro lado, postulam liberdade e se regulamentam pelo dever-ser, sob o princípio de uma teleologia moral imperativa.

Tal debate entre o determinismo e a teleologia tomou, durante a segunda metade do século XIX, a forma mais específica de uma questão acerca da possibilidade e da pertinência cognoscitiva da explicação (causal) ou da imprecisão (dos fins e do sentido das ações) no método histórico-social. Ele foi importante para o nascimento de uma "história compreensiva", a qual provocou o renascimento da hermenêutica (Schleiermacher), assumida como o método próprio da filosofia clássica e, por extrapolação, da historiografia romântica alemã. Consequentemente, o cânone hermenêutico da compreensão do "texto pelo contexto" foi assumido pela história num duplo sentido: 1) os fatos históricos e suas obras só podiam ser compreendidos situando-os como momentos e componentes de uma totalidade estrutural e em processo (época, sociedade, cultura, personalidade etc.); 2) tais eventos e obras eram produtos dessas totalidades cuja dinâmica obedecia não só a princípios racionais teóricos ou práticos, senão que se desenvolvia com o impulso de "toda a alma", do "ser inteiro", remarcando, assim, a influência histórica da tradição, do sentimento e, particularmente, dos valores e fins livremente decididos e não necessariamente fundados de maneira

\footnotetext{
${ }^{13}$ Do ponto de vista social, a devoção apolítica aos poderosos como pré-condição para a introspecção e a rejeição germânica do mundo prefigura, talvez, o traço mais marcante da cultura alemã a partir de então, sabendo que suas origens advêm da influência da figura de Lutero e de sua reforma social e religiosa. Noutras palavras, o indivíduo autodidata (incomparável e não meramente intelectual) era sempre descrito como absolutamente único e imbuído de potencial distintivo para a realização pessoal.
} 
racional. É o momento no qual se fala de "espírito da nação", "espírito das leis", "espírito do capitalismo" etc.

Dessa perspectiva, o ato de conhecimento próprio da história era "com preender o sentido" dessa totalidade no "espírito" (Geist) em movimento. E, uma vez capturada a teleologia de uma época, de uma cultura, de uma sociedade ou de uma personalidade, se podia explicar a aparição real e a configuração peculiar de certos fatos particulares: do todo à parte, do real à análise conceitual. Explicar os fatos significava compreendê-los como condições, instrumentos ou consequências do desenvolvimento teleológico de uma totalidade "espiritual".

Para estabelecer essa questão em uma forma e em um nível diferentes foi decisivo o retorno a Kant, na segunda metade do século XIX, o que foi proposto por Dilthey e realizado com maior ênfase pelos neokantianos da Escola de Baden (Windelband e Rickert, por exemplo). ${ }^{14}$ Assim como Kant pretendeu dar conta da física e da matemática de seu tempo, a escola neokantiana de Baden pretendeu fazer o mesmo com as nascentes disciplinas histórico-sociais que em Kant ficaram fora da ciência ou submissas à regularização ético-jurídica racional. A “crítica da razão histórica", sem abandonar os princípios da teoria "transcendental" do conhecimento, tomou a forma de uma axiologia transcendental e, mais especificamente, a forma de um "interesse" ou "valor" de conhecimento que presidia e determinava a orientação e o exercício do método. A Escola de Baden refutou que o objeto determinara o método - posição mantida por toda a escola histórica e aguçada por Dilthey - e, inversamente, afirmou que o valor ou o interesse do conhecimento conduzia a diversos processos de formação ou elaboração do conceito dos objetos dados empiricamente.

Com isso, a ciência histórico-social mergulhou na filosofia, uma vez que os neokantianos esquentaram o debate e apontaram novas propostas que podiam ser retomadas e reinterpretadas sem a necessidade de aceitar ortodoxamente suas premissas e conclusões.

\footnotetext{
${ }^{14} \mathrm{O}$ famoso discurso reitoral de Wilhelm Windelband sobre História e ciências naturais, de 1894, manifestou uma nova linha analítica neokantiana - aperfeiçoada e reelaborada mais tarde por Heinrich Rickert -, transferindo o enfoque do princípio de empatia para o princípio de individualidade. E apesar de Windelband praticamente ignorar a psicologia descritiva e as reflexões sobre as disciplinas humanistas de Dilthey, defendia que se devia reduzir o estudo das questões humanas à busca de regularidades psicofísicas - o que Weber considerava e condenava como formas de "psicologismo".
} 


\section{Intervenção de Weber no debate historicista}

Esta será a tarefa metodológica de Max Weber - notadamente, um vigoroso neokantiano -: como fundar uma ciência historicista da história social, tendo como apoio a sociologia e a filosofia.

Consciente das hipóteses filosóficas que pesavam nas investigações historicistas, Weber se opõe a toda teologia (judaico-cristã), ontologia e axiologia que tiveram pretensões de alcançar a universalidade e o absoluto na determinação do princípio e do sentido da história. Weber fará suas as exigências historicistas relacionadas com a "compreensão do sentido", com o "indivíduo histórico", a teleologia, o "universal concreto", mas, ao mesmo tempo, intentará reelaborálas de maneira que não excluam a necessidade do conceito, a formação de enunciados causais e a comprovação empírica dos mesmos.

Com Weber, o tema da "racionalidade" recupera a "razão" dentro do historicismo, sem denotar com isso que o real e o racional, o cronológico e o lógico coincidam. A racionalidade é apenas uma estratégia metodológica para facilitar conceitualmente a compreensão hermenêutica dos fatos históricos. Ela possui uma função heurística.

Ele acrescentará ainda que os fatos histórico-sociais devem ser explicados a partir da premissa de que eles são consequências de ações e que as ações são a realização de certos fins mediante o emprego de certos meios. Por conseguinte, a explicação causal da aparição de determinados fatos se baseia finalmente na compreensão do sentido da ação do agente histórico.

Ou seja, um dos significativos feitos teóricos de Weber - que nos ajuda a entender sua empreitada - foi a integração de duas perspectivas divergentes que vinham dividindo teóricos e profissionais das ciências históricas, sociais e culturais desde o início do século XIX: as chamadas abordagens interpretativista e explicativa. A barreira entre ambas apareceu em outras épocas e contextos científicos, mas foi particularmente acentuada na cultura acadêmica de Weber. $\mathrm{Na}$ verdade, seus resíduos ainda constituem sérios obstáculos ao pensamento intelectual e isso nos proporciona um maior crédito para análise.

Ao nosso modo de ver, Weber teria resolvido a tensão - operando, assim, a união entre ciências culturais e historicismo - por meio de duas reformulações cruciais, e, no que mais nos importa, com seu olhar também (e porque não dizer, principalmente) voltado à Índia. Para começar, adotou um esquema intricado e flexível de análise causal singular; um tipo de análise que o faz remontar a seus antecessores causais pertinentes, a determinados eventos e às mudanças 
históricas ou desfechos. Depois, ao longo dessa linha de análise, desenvolveu um modelo de interpretação baseado na atribuição hipotética de racionalidade, o qual independe de pressupostos subjetivos e naturalistas, ao mesmo tempo em que redime o processo hermenêutico como uma forma de análise causal singular.

Essa íntima conexão entre interpretação e explicação, no pensamento weberiano, é ainda ilustrada por sua recomendação de tipos ideais como recursos heurísticos. Tais tipos ideais são simplificações ou caracterizações unilateralmente exageradas de fenômenos complexos, os quais podem ser hipoteticamente concebidos e depois comparados com a realidade que devem elucidar. Como exemplo, Weber encontrará na Índia o extremo-oposto do judaísmo, do protestantismo e do capitalismo moderno, ${ }^{15}$ uma vez que ela representa o que há de mais encantado, mágico e substancialmente vivo, portanto, um objeto privilegiado para suas comparações.

Weber dispôs-se a explicar a "combinação de circunstâncias", a qual foi responsável pela diferenciação inicial entre a cultura ocidental e a oriental. Isto fica evidente quando a contemplação mística e a filosofia - especialmente tal como se desenvolveu na Índia - é posta em contraste, ponto por ponto, com o ascetismo interior, tal como se desenvolveu no cristianismo ocidental; enfatizando que o ascetismo puritano, por exemplo, viola o metafísico, em contraposição ao pensamento budista antigo que encara a ação deliberada como uma forma perigosa de secularização.

Nas primeiras linhas de Das antike Judentum, ${ }^{16}$ Weber também dirá que a conduta social e ritual das castas indianas antigas - para as quais o mundo é eterno e carece de "história" linear ou típica ocidental - é justamente o oposto da conduta judaica antiga, pois, para esta, o ordenamento social do mundo é visto como algo que confirmaria a eleição escatológica do povo judeu como dominador da terra. O que provocara, segundo Weber, "uma distância enorme" e evidente entre o pensamento judaico e o indiano. Evidência estabelecida na explícita dicotomia em relação à visão do tempo (judaica, linear-finalista; indiana, cíclica); na visão da magia (judaica, antimágica; indiana, totalmente mágica); e assim sucessivamente em relação ao trabalho, à mulher, à política, à comensalidade, à economia, à sexualidade, à filosofia etc.

Como assinalado anteriormente, além do judaísmo, Weber coloca em pauta o protestantismo frente à Índia, pois somente o protestantismo ascético efetiva-

\footnotetext{
${ }^{15}$ Assim como o confucionismo será o "espírito" mais próximo do puritanismo.

${ }^{16}$ WEBER, Max. Gesammelte Aufsätse zur Religionssoziologie, t. III. Tübinger: Mohr, 1978.
} 
mente eliminou a magia e a "iluminação" contemplativa intelectualista, que, na verdade, representa o oposto da concepção de profissão hinduísta tradicionalista, ou seja, um mundo tal qual "um grande jardim encantado". ${ }^{17}$

Todavia, esta comparação entre opostos extremos, a qual Weber elaborou com sua indologia, não foi tomada como contribuição para a precisão de suas construções analíticas, além de não ser considerada como ciência histórica, como hoje podemos caracterizar boa parte de sua obra. Pois, assim como em Die protestantische Ethik, em Hinduismus und Buddhismus, Weber exagera seus exemplos e elucida definitivamente seu método e seus pressupostos. Mas, com tudo isso, a Índia de Weber ficou, além de praticamente silenciosa, reduzida a um apêndice da sociologia.

Supomos que essa ausência (ou silêncio) da indologia weberiana deveu-se a algumas razões. Por exemplo, alguns indólogos modernos equivocadamente consideram, por um lado, que o trabalho de Weber não contribui com nada significativamente profundo sobre a Índia; e, por outro, que está cheio de imprecisões, clichês e erros. ${ }^{18}$ Mas isto se deve, em especial, ao fato de tal pesquisador não conhecer em especial a teoria da racionalidade weberiana e suas devidas comparações analíticas em torno da Ásia. Além disso, Hinduismus und Buddhismus lhes põe a dificuldade - muito mais do que outras obras - de se ter em conta as linhas fundamentais dos desenvolvimentos teóricos weberianos, acrescidas da exigência de conhecimento razoável da cultura indiana e principalmente da língua sânscrita (exaustivamente utilizada por Weber, muitas vezes sem tradução ou aparato conceitual de apoio) - quase sempre não familiar aos pesquisadores ocidentais -, para relacioná-los e compreendê-los.

Como diz David Gellner, ${ }^{19}$ muitos estudiosos (ocidentais) de Weber possuem em Hinduismus und Buddhismus sua única fonte de conhecimento sobre a Índia. Isso revela um problema tanto para o entendimento da indologia de Weber quanto para o pressuposto teórico de um Weber historiador.

\footnotetext{
${ }^{17}$ Idem. Wirtschaft und Gesellschaft: Grundriss der verstehenden Soziologie. Türbingen: Mohr, 1985 , p. 379.

${ }^{18}$ KULKE, Hermann. Max Weber's contribution to the study of hinduization in India and indianization in Southeast Asia. In: KANTOWSKI, D. (ed.). Recent research on Max Weber's studies of hinduism. Munich: Weltforum Verlag, 1986, p. 97.

${ }^{19}$ GELLNER, David. Max Weber, capitalism, and the religion of India. In: HAMILTON, P. Max Weber: critical assessments 2, vol. IV. London: Routledge, 1991, p. 247-267.
} 
Não obstante, Weber se apropriou das exigências metodológicas do historicismo alemão, contra toda filosofia iluminista da natureza humana (Wilhelm Ostwald e Karl Lamprecht) e contra toda filosofia idealista da história. Todavia, as depurou no intuito de evitar as conclusões do romantismo (Friedrich Schlegel e Friedrich Rückert, ambos orientalistas) e os desvios psicologistas do neo-historicismo (Schmoller, Wundt e Lujo Brentano). Com isso, muniu-se de um método particular, resgatou o tema da racionalidade e o utilizou como parâmetro para compreender a sociedade ocidental. Além disso, tendo como base seu método compreensivo e comparativo, e estando inserido numa sociedade contagiada pela Índia, ${ }^{20}$ não se limitou ao Ocidente - fato que também o motivou a introduzir em suas análises sócio-históricas o método comparativo entre as culturas (principalmente entre as éticas religiosas) ocidentais e orientais. Seu método não só preconizava uma abordagem causal do mundo cultural e social, como ainda via a "cadeia de causas" históricas movendo-se em direções divergentes e ocasionalmente opostas, dependendo das circunstâncias, o que o levou a comparar as culturas ocidentais com as orientais, sem conjecturas evolucionistas. Assim elucida Colliot-Thélène, ao analisar Weber nesse aspecto:

Cada um dos aspectos de nossa civilização [ocidental] se encontra, assim, posto em evidência através da comparação com os aspectos correspondentes em outras civilizações, anteriores ou desconhecidas, os quais se acham reduzidos ao estatuto de imagens invertidas. ${ }^{21}$

Por tamanha ousadia metodológica, Paul Veyne dirá que "a obra histórica mais exemplar do nosso século [XX] é a de Max Weber, que apaga as fronteiras entre a história tradicional, da qual tem o realismo, a sociologia, da qual tem as ambições, e a história comparada, da qual tem a envergadura". ${ }^{22}$ A exemplo de Peter Burke, ${ }^{23}$ que afirma: "no que respeita a Max Weber, a amplitude e a profundidade dos seus conhecimentos históricos eram verdadeiramente fenomenais". Tamanha profundidade, comenta François Dosse, ${ }^{24} \mathrm{o}$ faz atualmente beneficiar-

\footnotetext{
${ }^{20}$ Principalmente, com a descoberta do sânscrito, da poesia, da literatura, da mitologia, da filosofia e da religião indianas.

${ }^{21}$ COLLIOT-THÉLÈNE, Catherine. Max Weber e a história. São Paulo: Brasiliense, 1995, p. 77.

22 VEYNE, Paul. Como se escreve a história. Lisboa: Edições 70, 1983, p. 319.

${ }^{23}$ BURKE, Peter. Sociologia e história. Porto: Edições Afrontamento, 1980, p. 16.

${ }^{24}$ DOSSE, François. A história. São Paulo: Edusc, 2003, p. 97.
} 
se "de um grande ganho de interesse, espetacular, na França". José Carlos Reis sugere que: "os Annales parecem dever mais a Weber do que querem admitir". ${ }^{25}$

Veyne acrescentará que Weber - para quem a história é relação de valores não procura, na verdade, estabelecer as leis ou regras de suas comparações (sociologia), mas aproxima e classifica os casos particulares de um mesmo tipo de fato através dos séculos, utilizando-se do fator tempo como prerrogativa de sua epistemologia (história). O que fica evidenciado em sua análise do mundo asiático.

\section{A Ásia weberiana}

A Ásia é para Weber um verdadeiro jardim encantado, uma terra de livre convivência entre as religiões, de tolerância no sentido helênico e de um real conjunto de coexistências de cultos, escolas e ordens de todo tipo. Ele ressalva que também aconteceram as disputas armadas, os conflitos políticos e as perseguições religiosas, principalmente na China, mas tudo isso não tira o encanto dos intercâmbios mútuos que cultivaram diversas formas de soteriologias, para as diversas camadas sociais.

Weber acrescenta que, com pouquíssimas exceções, as soteriologias asiáticas oferecem promessas apenas acessíveis àqueles que levam uma vida exemplar (no caso indiano, acessíveis de acordo com o cumprimento do dever ritual específico). Todos participam de alguma forma, todos possuem uma esperança e um dever em torno dela. No entanto, a intelectualidade tem sido sempre o guia de toda prática asiática, a mola mestra das motivações, a categoria que eleva e transcende, a camada que detém os modelos extremados do agir religioso e o desabrochar das inquietações sociais e filosóficas. Os intelectuais na Ásia sempre deram os primeiros passos quando munidos de certezas e nunca foram pensadores meramente teóricos, mas sempre os infantes de suas teorias. Eles foram os modelos dos demais e sempre chegaram ao topo do possível e desejado.

AÍndia, em particular, diz Weber, é o país típico dessa luta intelectual e inquietante, única e exclusivamente por uma cosmovisão no sentido próprio da palavra: por um sentido da vida no mundo. E acrescenta ele: "não há absolutamente nada no âmbito do pensamento sobre o 'sentido' do mundo e da vida que não tenha sido já pensado de alguma forma na Ásia". ${ }^{26}$ Desta forma, no pensamento webe-

${ }^{25}$ REIS, José Carlos. A história entre a filosofia e a ciência. São Paulo: Editora Ática, 1996, p. 78.

${ }^{26}$ WEBER, Max. Ensayos sobre sociología de la religión, t. II. Madrid: Taurus, 1987, p. 348 [Hinduismus und Buddhismus, Tübingen: J. C. B. Mohr., 1996, p. 528]. Tal passagem podemos encontrar em COHN, Gabriel. Weber. Coleção Grandes Cientistas Sociais, n. 13. São Paulo: Ática, 1999, p. 144. 
riano, todo o sentido da vida, da libertação do mundo, dos afazeres cotidianos, das festas, dos anseios e dos devaneios são moldados pelo pensamento especulativo, pelo caráter da gnose que agita intensamente o homem asiático. Toda a soteriologia asiática, portanto, está no âmbito do saber e é a porta de entrada para a libertação suprema, ao mesmo tempo em que um excepcional caminho para o reto agir; por isso, ela é sempre vista como a guia que conduz toda a sociedade.

Só o saber, diz Weber, dá ao homem asiático poder ético e mágico sobre si mesmo e sobre os demais. E este é um saber geralmente irracional e algumas vezes relativamente racional - como no caso da doutrina indiana do karma e do saàsära -, mas nunca um estudo de conhecimento típico ocidental, senão um meio de domínio místico e mágico sobre si e sobre o mundo, como bem caracterizado pelo Yoga indiano.

\section{A Índia aporta à compreensão das ideias de Weber}

Sérgio da Mata, ${ }^{27}$ um dos maiores defensores do Weber historiador no Brasil, elucida que o alemão continua a ser conhecido como sociólogo, apesar de ter escrito parte substancial de sua obra na condição de historiador - como bem expresso em Hinduismus und Buddhismus -, assim como de analista de complexos problemas relativos à lógica do conhecimento histórico.

Mas se tal obra foi intitulada Religionssoziologie [sociologia da religião], como se explica que ela é historicista? Mata $^{28}$ explicará que, dos três volumes dos mencionados ensaios, exclusivamente o primeiro foi efetivamente organizado por Weber. E na nota preliminar do primeiro volume, em nenhum momento Weber caracteriza o conjunto dos trabalhos ali incluídos, bem como sua sequência de volumes, como obra sociológica. Ao contrário, continua a explicar Mata, ele fala muito mais de abordagem "histórico-cultural" ou "históricouniversal”. O que implica confirmar, a priori, que o título Gesammelte Aufsätse zur Religionssoziologie [Ensaios reunidos de sociologia da religião] não tenha sido nomeado por Weber. Não sendo por acaso que a edição mais completa de Hinduismus und Buddhismus seja recolhida com o título: Die Wirtschaftsethik der Weltreligionen [A ética econômica das religiões mundiais], tomo $20 \mathrm{da}$

\footnotetext{
${ }^{27}$ MATA, Sérgio da. O mito de A ética protestante e o espírito do capitalismo como obra de sociologia. In: Locus, revista de história. Juiz de Fora, v. 12, n. 1, 2006.

${ }^{28}$ Ibid., p. 125.
} 
seção I, de Max Weber Gesamtausgabe [Edição completa de Max Weber], de 1996, elaborada com o apoio de Karl-Heinz Golzio.

Todavia, a esposa de Weber (Marianne) juntamente com o editor Paul Siebeck interferiram profundamente na edição da obra weberiana, guiando-a por critérios próprios, dirá Mata. Muitos dos títulos das seções de Economia e sociedade, por exemplo, foram inventados por eles. De forma que há fortes indícios para se concluir que seja de responsabilidade de ambos, e não de Weber, a "sociologia" incluída no título dos Ensaios. Mata apontará um indício neste sentido:

Numa carta a Siebeck, 24 de maio de 1917, Weber diz estar retrabalhando os textos que deveriam ser publicados, após a guerra, em suas "obras completas" [Gesamtausgabe]. E acrescenta, numa clara menção ao título da futura obra: "ou, se você preferir: os 'ensaios reunidos"” [Gesammelten Aufsätze]. Nem uma palavra, portanto, sobre sociologia da religião. ${ }^{29}$

Segundo Marriane, ${ }^{30}$ Weber iniciou suas análises indológicas em 1911 - para Turner, ${ }^{31}$ em 1910 - e uma primeira versão de Hinduismus und Buddhismus ficou pronta em 1913, tendo a elaboração final do mesmo em 1915 e início de 1916, quando Weber residia em Berlim. Em 1919, a obra já estava pronta para ser impressa e, em 6 de fevereiro de 1921, quase seis meses após a morte de Weber, eis que surge a primeira versão em livro.

Tal obra será uma das investidas weberianas mais proeminentes, como singular demonstração de seu método histórico comparativo e diagnóstico de um particular desencanto (racionalização burocrática e tecnocrática) ocidental e puritano versus a Índia, sua "encantadíssima Índia".

A Índia, no arguto olhar weberiano, é a terra natal do atual sistema racional (fundamento de toda calculabilidade, matemática e gramática) ocidental, o qual manifestou na condução da guerra, da política e da economia - todas circundadas de um racionalismo que acompanha a literatura que as teoriza, a Arthashastra. Uma terra onde tanto a guerra cavalheiresca (yuddham) como os exércitos disciplinados (danda) tiveram sua época; onde o arrendamento dos impostos (kara-dandayoh) e o desenvolvimento

\footnotetext{
${ }^{29}$ Ibid.

${ }^{30}$ WEBER, Marianne. Weber: uma biografia. Rio de Janeiro: Casa Jorge Editorial, 2003, p. 396; Max Weber: ein Lebensbild. Tübingen: Mohr, 1984, p. 396.

${ }^{31}$ TURNER, Bryan. For Weber. Essays on the sociology of fate. London: Routledge, 1981.
} 
das cidades (jana-padah) nada deviam ou se distinguiam do patrimonialismo ocidental; bem como o cultivo da ciência racional (sankhya), de escolas filosóficas (darshanas) e da consequente metafísica profunda (Yoga). ${ }^{32}$

Dirá Weber:

O atual sistema numérico racional, fundamento técnico de toda "calculabilidade", é de origem indiana. Os indianos [...] cultivaram a ciência racional (e entre ela, a matemática e a gramática). Também tiveram a experiência do desenvolvimento de numerosas escolas filosóficas e religiosas, de quase todos os tipos sóciohistoricamente possíveis. Em boa medida, surgiram estas sobre o substrato de uma poderosa tendência ao intelectualismo e à racionalidade sistemática que se apoderaram dos mais diversos domínios da existência. ${ }^{33}$

Em todo caso, afirma Weber: "jedenfalls ungleich größer als irgendwo im Occident vor der allerneusten Zeit" [infinitamente maior que em qualquer parte do Ocidente antes da idade contemporânea], ${ }^{34}$ e como em nenhum outro lugar ou cultura. Além disso, continua o autor, a Índia também é a região onde o artesanato (karu) e a especialização dos ofícios (vanijyam) alcançaram estágios grandiosos; onde, como em nenhum outro lugar, apreciou-se tanto a riqueza (Lakshmi) sem, por outro lado, cair nos ditames de uma ética econômica (com afã de lucro ou Erwerbstrieb) tipo capitalista (particular da modernidade protestante) ou do desencantamento do mundo (Entzauberung der Welt), o qual - este último - caracterizado por Weber como o mecanismo desdivinizado do mundo, através do qual (do protestantismo à ciência profissionalizante moderna) se chega ao reducionismo do mundo com seu mecanismo causal desmagicizante, tecnocrata e burocrata.

\footnotetext{
${ }^{32}$ Lembrando que a terminologia Yoga nada, ou quase nada, tem em relação com o que se observa nas academias estéticas ocidentais atuais, pois Yoga, termo que designa a forma-propulsora do pensamento indiano clássico, deriva da raiz sânscrita yuj, "ligar", "manter unido", "atrelar", "jungir", a qual originou o termo latino jungere, jungum e o inglês yoke. Yoga designa, evidentemente, um liame; e a ação de ligar-se ao Absoluto pressupõe, como condição primeira, a ruptura dos liames que unem o espírito ao mundo, ou seja, um estado mental e corpóreo prévio, capaz de promover uma emancipação ou união de si com a metafísica (como coisa em si ou representada numa personalidade ou energia transcendente).

${ }^{33}$ WEBER, Max. Ensayos sobre sociología de la religión, t. II. Madrid: Taurus, 1987, p. 13; Die Wirtschaftsethik der Weltreligionen. Hinduismus und Buddhismus. Schriften 1916-1920 (20). In: Max Weber Gesamtausgabe. Tübinger: Mohr, 1996, p. 54.

${ }^{34}$ Ibid.
} 
Weber também nos apresenta uma Índia onde as éticas religiosas de negação do mundo (como o budismo), seja teórica ou praticamente, e com a maior das intensidades, deram margem, originaram e desenvolveram a contemplação extramundana, a ascese e o monasticismo, manifestando-se de forma mais coerente e dando início a um caminho histórico que se espalhara por todo o mundo. Essa é a Índia de Weber: original, sempre cobiçada e ao mesmo tempo racional e mágica; uma verdadeira terra de filósofos e pensadores inquietos, sempre inquietos! ${ }^{35}$

Todavia, a Índia, como todo o passado humano antes do advento do protestantismo, segundo Weber, não desenvolveu uma racionalidade "com sua 'vocação profissional' entendida como missão, exatamente como dela precisa o [espírito do] capitalismo". ${ }^{36}$ Mas ele não encara tal fato como desenvolvimento ou evolução, pelo contrário, vê nessa empreitada única do ocidental puritano um desencanto, o qual provocará a retirada dos valores mais sublimes e essenciais da vida pública, surgindo o que ele denomina de "especialistas sem espírito" e "gozadores sem coração: esse Nada [homem moderno que] imagina ter chegado a um grau de humanidade nunca antes alcançado". ${ }^{37}$ Para Weber, tal homem moderno, esse Nada, em tais circunstâncias, está destinado a viver em uma época desencantada: sem deuses nem profetas. ${ }^{38}$

Com o advento da indologia na Europa, principalmente na Alemanha romântica, a Índia deixará de ser uma matéria de especulação livre e passará a ser uma disciplina ministrada com regras rígidas, não obstante, etnocentricamente hegelianas para os não-orientalistas. Weber será o único intelectual não-orientalista ${ }^{39}$

${ }^{35}$ Uma Índia que contradizia, e muito, aquela que Hegel apresentara; justificava a que Schopenhauer e os românticos alemães ovacionavam; e se assemelhava muito com a Índia das castas e do código de leis de Manu em Nietzsche, o qual resume as castas naquela que "formula a lei maior da própria da vida" (NIETZSCHE, Friedrich W. O anticristo \& ditirambos de Dionísio. São Paulo: Companhia das Letras, 2007, § 57) e contrapõe o hinduísmo com o cristianismo: "é com o sentimento oposto [à Bíblia] que leio o código de Manu [o mais antigo código de leis conhecido], uma obra inigualavelmente espiritual e superior, tanto que apenas nomeá-lo juntamente com a Bíblia seria um pecado contra o espírito. Logo se percebe: ele tem uma verdadeira filosofia atrás de si, em si, não apenas uma malcheirosa judaína [ópio judaico] de rabinismo e superstição [...]" (Ibid., § 56-57, grifos do autor).

36 WEBER, Max. A ética protestante e o "espirito" do capitalismo. São Paulo: Companhia das Letras, 2004, p. 68.

${ }^{37}$ Ibid., p. 166.

${ }^{38}$ Idem. La ciencia como vocación. In: GERTH, Hans \& MILLS, Carl Wright (eds.). Ensayos de sociología contemporánea. Barcelona: Martínez Roca, 1975.

${ }^{39}$ Não-orientalista, no sentido de não ter o Oriente como foco principal, mas ao mesmo tempo tendoo como ambiente sócio-intelectual comparativo ao desencantamento do mundo na modernidade. 
ligado à investigação histórica ${ }^{40}$ que tentará transgredir as barreiras impostas pelo academicismo indológico alemão com raízes hegelianas, ${ }^{41}$ combatendo intelectualmente a filosofia da história que desqualificava integralmente a Índia como sem qualquer fundamento de ideias profundas. Tal desqualificação, como nos alerta Bermejo Barrera, ${ }^{42}$ expressava aqueles elementos que constituem a ideia clássica da história universal: a unidimensionalidade política, o caráter linear do progresso, o caráter sexista que exclui a mulher da história, a supressão ou rebaixamento do "outro" não-ocidental e não-cristão, o caráter providencial que reflete a ideia de que vivemos no melhor dos mundos históricos possíveis onde tudo cumpre uma função e é necessário; e, por fim, o etnocentrismo que sustentou o discurso - por meio de inúmeras ciências, inclusive da História - do colonialismo e da superioridade do homem branco e europeu.

\section{Conclusão}

Frente à história universal, portanto, Weber não verá o não-ocidental ou nãocristão como o "outro"; ele não tratará o Oriente, por exemplo, como primitivo ou subdesenvolvido, o qual permanecerá estancado até seu encontro com o Ocidente europeu. Em seus estudos da Índia, por exemplo, o Ocidente aparecerá apenas como contraste e sempre como a região do mundo que se desencantou, que perdeu valores necessários para a sociedade. Até mesmo o uso dos termos "racional" e "irracional" não estará associado a uma dicotomia: Ocidente (racional) e Oriente (irracional); pois, a própria ideia weberiana de "racionalidade" se divide em racionalismo conceitual e racionalismo pragmático - o primeiro relacionado com o domínio teórico da realidade através de conceitos abstratos cada vez mais precisos, e o segundo, num sentido de artifício metódico de um objetivo prático, determinado através de um cálculo cada vez mais conciso dos meios adequados. Ambos são muito diferentes. Nas palavras de Laurent Fleury, Weber

\footnotetext{
${ }^{40} \mathrm{Na}$ filosofia, Schopenhauer e Nietzsche farão sua parte.

${ }^{41}$ Muitos pensadores alemães, e em parte Marx, olharam para a Índia com preconceito e desdém; com um olhar típico eurocêntrico, semelhante aos cristãos portugueses que a invadiram com suas prerrogativas sentimentalistas. Tais pensadores não a compreenderam ou mal interpretaram-na, ora por não absorverem significativamente o sistema social (varnasrama), a lógica (nyaya), a ciência (sankhya), a filosofia (darshana) e a religião (dharma ou "dever ritual" hindu, budista ou jainista) indianas, ora por constatarem inúmeras contradições e insuficiências entre a Índia como objeto e seus métodos analíticos.

${ }^{42}$ BARRERA, J. C. Bermejo. Genealogía de la historia. Ensayos de historia teórica III. Madrid: Akal, 1999.
} 
"compreende que o que pode ser considerado racional a partir de determinado ângulo pode inversamente ser julgado como irracional de outro. Por outras palavras, Weber não separa [em certo sentido] a racionalidade e a irracionalidade". ${ }^{43}$

Ou seja, conclui Fleury,

apesar da ideia da especificidade ocidental, Weber evita a armadilha do etnocentrismo. De fato, estuda estas civilizações com neutralidade, qualificando o elo que une o comportamento dos indivíduos às formas econômicas, às estruturas sociais e às instituições políticas. Adota uma posição antievolucionista pela sua recusa da ideia de progresso e de leis dialéticas de uma história universal, linear e necessária. Insiste num encadeamento de circunstâncias, nos cruzamentos recíprocos de fatores e na simultaneidade das contingências temporais. Este pluralismo causal elimina tudo o que é unívoco [...]. ${ }^{44}$

Isto para a época - e ainda para nós - representa uma verdadeira revolução intelectual e uma alternativa à filosofia da história.

Andreas Buss ${ }^{45}$ também nos elucida que para analisarmos a posição weberiana frente ao âmbito asiático, devemos ter em conta uma série de fatores. Primeiramente, a atitude weberiana diante da sociedade moderna (com sua visão lúgubre do capitalismo e do suposto progresso ocidental) pode resultar surpreendente para a sua época, pois o mesmo já combatia as teorias etnocêntricas, as quais etiquetavam de irracionais as religiões orientais. Weber estava convencido da originalidade e da importância universal da sociedade ocidental europeia e moderna, caracterizando-a como racional e burocrática, ao mesmo tempo em que observa o efeito do hinduísmo e do budismo sobre a vida econômica indiana, atribuindo, concomitantemente, um alto grau de racionalidade a suas teodiceias, práticas religiosas, modo de vida e filosofia. Parece claro, portanto, segundo Buss, que por sua atitude ambivalente frente ao capitalismo, à ciência e à sociedade ocidental em geral, Weber não havia usado nunca o Ocidente como exemplo para o Oriente.

Em segundo lugar, muitos autores viram nas obras de Weber uma defesa do colonialismo e do domínio imperialista ocidental, o qual havia amparado sua suposta superioridade racional. No entanto, Weber em nenhum momento

\footnotetext{
${ }_{43}^{43}$ FLEURY, Laurent. Max Weber. Lisboa: Edições 70, 2003, p. 35.

${ }^{44}$ Ibid., p. 33.

${ }^{45}$ BUSS, Andreas. Max Weber and Asia. Contributions to the sociology of development. Munich: Weltforum Verlag, 1985.
} 
considerou o "outro" como irracional; nem sequer utilizou o termo "subdesenvolvido" ou "despótico", e muito menos subdesenvolvimento asiático ou indiano. Finalmente, Weber não queria passar uma imagem acabada de cada Weltreligion, senão falar das peculiaridades que servem de contrastes em relação a outras religiões, as quais, ao mesmo tempo, ajudam a entender as mentalidades econômicas. Em suma, Weber nos previne ante o otimismo do progresso presente no hegelianismo e marxismo, assim como diante da teoria da modernização, e se motiva a escrever uma história do processo da racionalização ocidental como uma perspectiva da patogêneses da modernidade, tendo como extremo comparativo intercultural: a Índia e seu esboço alternativo de sociedade. O que nos permite entender que Weber foi além das teorias dos sistemas vigentes, construindo uma perspectiva da história que possui indicadores sobre "como se podia afrontar o dilema da escrita histórica atual entre a Cila do enciclopedismo sem limites e a Caribdis das construções teleológicas". ${ }^{46}$ Vendo desta forma, Weber nos adverte que uma historiografia perspectiva não só deixaria que entrassem em conflito várias imagens históricas, como também animaria e permitiria um pluralismo de relações de valor.

Um dos aspectos mais originais da visão peukertiana é a importância que concede a perspectiva histórico-universal de nosso autor. Weber, reconhecida e consagradamente um dos nomes mais representativos da análise da história ocidental, especialmente da gêneses do capitalismo, aparece, nos últimos tempos, também como o pensador dos desenvolvimentos sociais e culturais asiáticos. Nesse ínterim, Mommsen apontará que, "em um certo sentido, não só se pode denominar Max Weber como historiador da cultura ou historiador social, mas também como historiador dedicado à história universal [Universalhistoriker]" ${ }^{47}$ Opinião semelhante também defendida por Astor Diehl: "em muitos sentidos, justifica-se citá-lo não apenas como historiador da cultura e historiador social, mas também como historiador do universal". ${ }^{48}$ E Diehl vai além, afirmando que

\footnotetext{
${ }^{46}$ PEUKERT, D. J. K. Max Weber diagnose der moderne. Gotinga: Vandenhoeck und Ruprecht, 1989, p. 40. Cila e Caríbdis são divindades aquáticas presentes na mitologia grega. Da narração sobre Cila e Caríbdis, surge a expressão: "estar entre Cila e Caríbdis", o que equivale dizer: "estar entre a cruz e a espada" ou "entre a espada e o muro", ou seja, estar diante de um problema complicado ou de dificílima solução.

${ }^{47}$ MOMMSEN, Wolfgang J. Max Weber. Gesellschaft, Politik und Geschichte. Frankfurt: Suhrkamp, 1982, 182.

${ }^{48}$ DIEHL, Astor Antônio. Max Weber e a história. Passo Fundo: UPF, 2004, p. 23.
} 
a construção dos tipos ideais de Weber é simultaneamente "história teórica e sociologia histórica com um extraordinário grau de abstração". ${ }^{4}$

O que leva Ringer a concluir:

É deveras significativo que alguns dos estudantes de Weber mais comprometidos na Alemanha atual sejam historiadores, e que tenha sido Weber quem inspirou a nova direção mais significativa na historiografia alemã contemporânea, historiografia que deu seguimento à análise comparativa da mudança estrutural. ${ }^{50}$

\section{Referências bibliográficas}

BARRERA, J. C. Bermejo. Genealogía de la historia. Ensayos de historia teórica III. Madrid: Akal, 1999.

BOURETZ, Pierre. Les promesses du monde: philosophie de Max Weber. Paris: Gallimard, 1995.

BURKE, Peter. Sociologia e história. Porto: Edições Afrontamento, 1980.

BUSS, Andreas. Max Weber and Asia. Contributions to the sociology of development. Munich: Weltforum Verlag, 1985.

COLLIOT-THÉLÈNE, Catherine. Max Weber e a história. São Paulo: Brasiliense, 1995.

COHN, Gabriel (org.). Weber. Coleção Grandes Cientistas Sociais, n. 13, São Paulo: Ática, 1999.

DIEHL, Astor Antônio. Max Weber e a história. Passo Fundo: UPF, 2004.

DOSSE, François. A história. São Paulo: Edusc, 2003.

ELIADE, Mircea. Yoga, imortalidade e liberdade. São Paulo: Palas Athena, 1996.

FLEURY, Laurent. Max Weber. Lisboa: Edições 70, 2003.

GELLNER, David. Max Weber, capitalism, and the religion of India. In: HAMILTON, P. Max Weber: critical assessments 2, vol. IV. London: Routledge, 1991, p. 247-267.

GLASENAPP, Helmut von. Die Philosophie der Inder. Stuttgart: Kröner, 1985.

GUSMÃO, Luís. A concepção de causa na filosofia das ciências sociais de Max Weber. In: SOUZA, Jessé. A atualidade de Max Weber. Brasília: UNB, 2000, p. 235-259.

HALBFASS, W. Indien und Europa. Perspektiven ihrer geistigen Begegnung. Stuttgart: Schwabe \& Co AG Verlag, 1981.

HEWA, Soma. The spirit of religion and the secular interest: Sri Lanka buddhism and Max Weber's thesis today. In: SWATOS, W. H. Twentieth-century world religious

\footnotetext{
${ }^{49}$ Ibid., p. 45.

${ }^{50}$ RINGER, Fritz. Metodologia de Max Weber: unificação das ciências culturais e sociais. São Paulo: Edusp, 2004, p. 162.
} 
movements in neo-weberian perspective. Lewiston: Mellen Press, 1992, p. 61-73. KANTOWSKY, Detlef (org.). Recent research on Max Weber's studies of hinduism. Munich: Weltforum Verlag, 1986.

KEITH, Arthur. The religion and philosophy of the Veda and Upanishads. Cambridge: Mass, 1925.

KULKE, Hermann. Max Weber's contribution to the study of hinduization in India and indianization in Southeast Asia. In: KANTOWSKI, D. (ed.). Recent research on Max Weber's studies of hinduism. Munich: Weltforum Verlag, 1986, p. 97-116.

LOVE, John. Max Weber's Orient. In: TURNER, S. (ed.). The Cambridge companion to Weber. Cambridge: Cambridge University Press, 2000, p. 172-199.

MacRAE, Donald. As ideias de Max Weber. São Paulo: Cultrix, 1988.

MATA, Sérgio da. O mito de $A$ ética protestante e o espírito do capitalismo como obra de sociologia. In: Locus, revista de história. Juiz de Fora, v. 12, n. 1, 2006, p. 113-126.

MOMMSEN, Wolfgang J. Max Weber, sociedad, política y historia. Buenos Aires: Alfa, 1981. 1982.

. Max Weber. Gesellschaft, Politik und Geschichte. Frankfurt: Suhrkamp,

NANDY, S. K. A critique of Max Weber's conception of the ethic of India. In: The Visvabharati Qaurterly, v. XXXII, 1966-1967, p. 277-304.

NIETZSCHE, Friedrich W. O anticristo \& ditirambos de Dionísio. São Paulo: Companhia das Letras, 2007.

OLIVEIRA, Arilson. Os mentores intelectuais do confucionismo, do taoísmo e do hinduísmo na perspectiva weberiana. In: Horizonte. PUC-Minas, v. 6, n. 10, 2007.

. Max Weber e a Índia: o vaishnavismo e seu yoga social em formação. São Paulo: Blucher Acadêmico, 2009a.

. Desvendando a religião e as religiões mundiais em Max Weber. In: Horizonte. PUC-Minas, v. 7, $\mathrm{n}^{\circ}$ 14, 2009b.

PEUKERT, D. J. K. Max Weber diagnose der moderne. Gotinga: Vandenhoeck und Ruprecht, 1989.

REIS, José Carlos. A história entre a filosofia e a ciência. São Paulo: Editora Ática, 1996.

RINGER, Fritz. Metodologia de Max Weber: unificação das ciências culturais e sociais. São Paulo: Edusp, 2004a.

. An intellectual biography. Chicago: The University of Chicago Press, 2004b.

RUSSELL, Bertrand. História da filosofia ocidental, vol. I. São Paulo: Companhia 
Editorial Nacional, 1957.

SCHLUCHTER, Wolfgang \& ROTH, Guenther. Max Weber's vision of history: ethics and methods. Berkeley: University of California Press, 1984.

. Paradoxes of modernity: culture and conduct in the theory of Max Weber. Stanford: Stanford University Press, 1996.

. As origens do racionalismo ocidental. In: SOUZA, Jessé (org.). $O$ malandro e o protestante: a tese weberiana e a singularidade cultural brasileira. Brasília: Editora UNB, 1999.

. Politeísmo dos valores. In: SOUZA, Jessé (org.). A atualidade de Max Weber. Brasília: Editora UNB, 2000, p. 13-48.

SINGER, Milton. Religion and social change in India: the Max Weber thesis, phase three. In: Economic Development and Cultural Change, vol. XIV, 1966, p. 497-505.

. Max Weber and the modernization of India. In: Journal of Developing Societies, vol. 1, 1985, p. 151-167.

SOUZA, Jessé (org.). O malandro e o protestante: a tese weberiana e a singularidade cultural brasileira. Brasília: Editora UNB, 1999.

. A atualidade de Max Weber. Brasília: Editora UNB, 2000.

TURNER, Bryan. For Weber. Essays on the sociology of fate. London: Routledge, 1981.

VEYNE, Paul. Como se escreve a história. Lisboa: Edições 70, 1983.

WEBER, Marriane. Max Weber: ein Lebensbild. Tübinger: Mohr, 1984.

. Weber: uma biografia. Rio de Janeiro: Casa Jorge Editorial, 2003.

WEBER, Max. The religion of India: The sociology of hinduism and buddhism. New York: Glencoe, 1958.

. Ciência e política: duas vocações. São Paulo: Cultrix, 1972.

. Gesammelte Aufsätse zur Religionssoziologie, tomo II. Tübinger: Mohr, 1978.

Wirtschaft und Gesellschaft: Grundriss der verstehenden Soziologie. Türbingen: Mohr, 1985.

. Ensayos sobre sociología de la religión, t. II, Madrid: Taurus, 1987.

. Die Wirtschaftsethik der Weltreligionen. Hinduismus und Buddhismus. Schriften 1916-1920 (20). In: Max Weber Gesamtausgabe. Tübinger: Mohr, 1996.

. A ética protestante e o "espírito" do capitalismo. São Paulo: Companhia das Letras, 2004.

Recebido: junho/2009 - Aprovado: setembro/2009. 